\title{
Quantitation and Radical Scavenging Activity Evaluation of Iridoids and Phenylethanoids from the Roots of Phlomis umbrosa (Turcz.) using DPPH Free Radical and DPPH-HPLC Methods, and their Cytotoxicity
}

\author{
Duc Dat Le ${ }^{1,2,3, \uparrow}$, Duc Hung Nguyen ${ }^{1,4, \dagger}$, Bing Tian Zhao ${ }^{1,5}$, Byung Sun Min ${ }^{1}$, Si Whan Song ${ }^{6}$, and Mi Hee Woo ${ }^{1, *}$ \\ ${ }^{I}$ Drug Research and Development Center, College of Pharmacy, Catholic University of Daegu, Gyeongbuk 712-702, Korea \\ ${ }^{2}$ Division of Computational Physics, Institute for Computational Science, Ton Duc Thang University, Ho Chi Minh City, Vietnam \\ ${ }^{3}$ Faculty of Pharmacy, Ton Duc Thang University, Ho Chi Minh City, Vietnam \\ ${ }^{4}$ Centre for Drug Research and Technology Transfer, Phutho College of Pharmacy, Viettri City, \\ Phutho Province 290000, Vietnam \\ ${ }^{5}$ School of Chemical and Material Engineering, Jiangnan University, Wuxi 214122, China \\ ${ }^{6}$ ChemOn Inc., Gyeonggi Bio-Research Center, Yongin, Gyeonggi 17162, Republic of Korea
}

\begin{abstract}
The roots of Phlomis umbrosa (Turcz.) (Phlomidis Radix) have been traditionally used to treat cold, reduce swelling and staunch bleeding. Four iridoids $(\mathbf{1}-\mathbf{3}$ and $\mathbf{5})$ and six phenylethanoid derivatives $(\mathbf{4}$, and $\mathbf{6}-$ 10) were isolated from the roots of P. umbrosa. A simple, sensitive, and reliable analytical HPLC/PDA method was developed, validated, and applied to determine 10 marker compounds in Phlomidis Radix. Furthermore, the isolates were evaluated for cytotoxic and anti-oxidant activities as well as DPPH-HPLC method. Among them, compounds 4 and 6-9 displayed potent anti-oxidant capacities using DPPH assay with $\mathrm{IC}_{50}$ values of 27.7 \pm 2.4 , $10.2 \pm 1.1,18.0 \pm 0.8,19.1 \pm 0.3$, and $19.9 \pm 0.6 \mu \mathrm{M}$, and compounds $\mathbf{6}, \mathbf{8}$, and $\mathbf{9}$ displayed significant cytotoxic activity against $\mathrm{HL}-60$ with $\mathrm{IC}_{50}$ values of $35.4 \pm 3.1,18.6 \pm 2.0$, and $42.9 \pm 3.0 \mu \mathrm{M}$, respectively.
\end{abstract}

Keywords - Phlomis umbrosa, antioxidant, developed HPLC/PDA method, cytotoxicity

\section{Introduction}

The genus Phlomis, perennial herbs of the Lamiaceae family, consists of more than 100 species distributed throughout Asia, Africa, and Europe. ${ }^{1,2}$ Phlomis umbrosa Turcz. [Korean name as Han Sok-Dan] is distributed in several countries of the Southeast Asia. The roots of $P$. umbrosa (Phlomidis Radix) have been traditionally used for treatment of the hemorrhage, bronchitis, and cold. ${ }^{3}$ Previous phytochemical investigations of the genus Phlomis have shown that they contain phenolics, iridoids, flavonoids, phenylethanoids, lignans, neolignans, diterpenoids, alkaloids and essential oils. ${ }^{4,5}$ The separation and determination of the active constituents in medicinal plant extracts represent a viable method to achieve standardization and quality control. However, multifarious constituents in the complex extracts of Phlomis species have

\footnotetext{
*Author for correspondence

Mi Hee Woo, College of Pharmacy, Catholic University of Daegu, Gyeongbuk 712-702, Korea.

Tel: +82-53-850-3620; E-mail:woomh@cu.ac.kr

†These authors contributed equally to this work
}

not been quantitated. Additionally, there is no report about the anti-oxidant and cytotoxic properties of the major constituents from the roots of $P$. umbrosa.

Nowadays, the chaotic use of two similar Korean traditional medicinal drug names between Sok-Dan (Dipsaci Radix, the roots of Dipsacus asperoides) and Han Sok-Dan (Phlomidis Radix, the roots of $P$. umborosa) has become a problem for affecting national health. However, the efficacies of these two traditional drug species are quite different. ${ }^{6}$ Concretely, Dipsasi Radix is used as a traditional medicinal plant for strengthening bone and healing fracture, whereas Phlomidis Radix has no effect on bone growth. ${ }^{7,8}$ Therefore, that is necessary to clarify for the avoidance of misusage between two herbs. There are several studies using HPLC development method to find bioactive constituents from medicinal plants. The aims of this study were focused on the isolation and the development of new HPLC analytical method for the major compounds from the roots of $P$. umbrosa. Additionally, their anti-oxidant activity was evaluated based on above developed method. Furthermore, the cytotoxic activity was also examined. 


\section{Experimental}

General experimental procedures - Unless specified, all used reagents were of analytical grade. The nuclear magnetic resonance (NMR) spectra were measured in methanol- $d_{4}$ on an Oxford AS $400 \mathrm{MHz}$ instrument (Agilent, Santa Clara, CA, USA). Column chromatography was performed on silica gel (Merck, Darmstadt, Germany; 63-200 $\mu \mathrm{m}$ particle size). Fractions were monitored by thin layer chromatography (TLC), and spots were visualized by spraying with ethanol containing $10 \%$ $\mathrm{H}_{2} \mathrm{SO}_{4}$, followed by heating. Gilson semi-preparative HPLC systems were carried out with an UV detector and an Optima Pak C18 column $(10 \times 250 \mathrm{~mm}, 10 \mu \mathrm{m}$ particle size, RS Tech. Corp., Korea). The quantitative analyses were conducted on an HPLC chromatography (Waters, Houston, TX, USA) and a Kinetex C18 column (4.6× $250 \mathrm{~mm}, 5 \mu \mathrm{m}$ particle size; Phenomenex, Torrance, CA, USA). Data handling was managed by Empower v.3.0 software.

Plant material collection - Five plant materials of $P$. umbrosa were identified and authenticated by Prof. Byung Sun Min. Samples 1-5 were marked as PU1PU5. Sample PU1 (Yeongwol-gun, Gangwon-do) was collected in March 2016, and used for isolation and validation. Four comparing samples (PU2 - PU5) were harvested in August 2016, at different geographic regions in Korea (PU2: Uiseong-gun, Gyeongsangbuk-do; PU3: Andong-si, Gyeongsangbuk-do; PU4: Yeongcheon-si, Gyeongsangbuk-do; PU5: Taebaek-si, Gangwon-do). The voucher specimens (PU1 - PU5) of the plants were deposited in Herbarium at College of Pharmacy, Catholic University of Daegu, Korea.

Isolation of the chemical constituents - The dried roots of P. umbrosa (PU1, $500 \mathrm{~g}$ ) were extracted with standing $80 \%$ ethanol $(10 \mathrm{~L} \times 3$ times $)$ at $80{ }^{\circ} \mathrm{C}$ for $5 \mathrm{~h}$. The combined water extract was filtered and concentrated in vacuo to afford water crude extract $(180 \mathrm{~g})$. This extract was then suspended in water $(6 \mathrm{~L})$ and partitioned between $\mathrm{H}_{2} \mathrm{O}$ and $n-\mathrm{BuOH}$ to give the $n-\mathrm{BuOH}$ fraction $(82 \mathrm{~g})$. The $n$ - $\mathrm{BuOH}$ fraction was chromatographed by using a silica gel column $(63-200 \mu \mathrm{m}$ particle size, $10 \times 120 \mathrm{~cm})$, eluting with a $\mathrm{CH}_{2} \mathrm{Cl}_{2} / \mathrm{MeOH} / \mathrm{H}_{2} \mathrm{O}$ gradient system (10: 1:0.1 to 1:1:0.1, each $5 \mathrm{~L}$ ) to yield six combined fractions (PU1 - PU5) according to their TLC profiles. Fraction PU3 (2.3 g) was purified by using a semi-preparative Gilson HPLC system [RS Tech Optima Pak C18 column $(10 \times 250 \mathrm{~mm}, 10 \mu \mathrm{m}$ particle size $)$; mobile phase ACN$\mathrm{H}_{2} \mathrm{O}$ containing $0.1 \%$ formic acid $(10-30 \%$ for $50 \mathrm{~min}$ ); UV detection at $247 \mathrm{~nm}$ ] to give compounds $4(5.1 \mathrm{mg}), \mathbf{5}$
(100 mg), 6 (72 mg), 7 (5.5 mg), 8 (6.7 mg), 9 (6.0 mg), and $10(8.3 \mathrm{mg})$. Similarly, fraction PU5 $(2.8 \mathrm{~g})$ was also purified by HPLC using a gradient solvent system ACN$\mathrm{H}_{2} \mathrm{O}$ containing $0.1 \%$ formic acid $(2: 98$ to $30: 70$ for 40 min) with UV detection at $247 \mathrm{~nm}$ to give compounds $\mathbf{1}$ (15 mg), 2 (110 mg), and 3 (10.2 mg).

Preparation of calibration standards solutions Standard stock solutions were prepared separately for each analytical standard and internal standard (IS) in $2 \mathrm{~mL} \mathrm{MeOH}$ at $1000 \mu \mathrm{g} / \mathrm{mL}$ and diluted with $\mathrm{MeOH}$ to obtain appropriate concentrations for content determination. The solutions were transferred to $10 \mathrm{~mL}$ glass brown vials, sealed using elastic plastic film (Parafilm, Chicago, IL, USA) and stored in a refrigerator $\left(4^{\circ} \mathrm{C}\right)$ for analysis.

HPLC instrument and chromatographic conditions The quantitative analyses were conducted on an HPLC chromatography (Waters, Houston, TX, USA) equipped with an autosampler, degasser, quaternary solvent pump, and photodiode array detector (PDA). Separation was carried out on a Kinetex C18 column $(4.6 \times 250 \mathrm{~mm}$, $5 \mu \mathrm{m}$ particle size; Phenomenex Torrance, CA, USA) protected by a C18 RP guard column $(10 \times 3.2 \mathrm{~mm}$, particle size $5 \mu \mathrm{m}$ ). The flow rate for mobile phase was set at $1 \mathrm{~mL} / \mathrm{min}$ and the injection volumes were $10 \mu \mathrm{L}$. UV detection was recorded at the wavelengths of 233 and $327 \mathrm{~nm}$. The mobile phase consisted of solvent $\mathrm{A}\left(\mathrm{H}_{2} \mathrm{O}\right.$ containing $0.1 \%$ formic acid) and solvent $\mathrm{B}(\mathrm{ACN})$, and gradient elution was conducted as follows: $7-35 \%$ (B) for $30 \mathrm{~min}$.

Method validation - The validation parameters of the developed HPLC-PDA method for the roots of $P$. umbrosa were linearity, limit of detection (LOD) and limit of quantitation (LOQ), accuracy, precision, stability, and robustness. Accurately weighed 10 markers were dissolved in methanol $1000 \mu \mathrm{g} / \mathrm{mL}$ to make stock solutions, which were then diluted to produce eight different concentrations for each marker. Linearity was determined by plotting the measurements of area peak ratios (analyte/IS) versus concentrations of analytical standards. The sensitivity was expressed by the LOD and LOQ. The LOD represents the lowest concentration that can be reliably determined at a signal-to-noise $(\mathrm{S} / \mathrm{N})$ ratio of 3 . The estimate for the LOQ was calculated using $\mathrm{S} / \mathrm{N}$ ratio of 10. Intra-day $(n=5)$ and inter-day $(n=5)$ precisions and accuracies were evaluated by analyzing sets of five independent samples at the low, mid, and high concentration levels. The precision was expressed as RSD\% and the accuracy was expressed as bias. The stability of analysis of isolated compounds was tested by analyzing the sample solution of roots of $P$. umbrosa through storing 
extract solution in the dark at $4{ }^{\circ} \mathrm{C}$ and room temperature $\left(25^{\circ} \mathrm{C}\right)$. The two samples were analyzed in triplicate at 0 , $1,3,7,15$, and 30 days separation.

Determination of DPPH-HPLC assay - The antioxidant activities of marker compounds in methanol extract were carried out using a DPPH-HPLC assay ${ }^{9}$ with a slight modification. Briefly, $180 \mu \mathrm{L}$ of DPPH solution ( $0.32 \mathrm{mM}$ in methanol) was added to $30 \mu \mathrm{L}$ of the methanol extract of $P$. umbrosa roots $(0.5 \mathrm{~g} / 25 \mathrm{~mL})$. After incubation for $15 \mathrm{~min}$ in a darkroom, the solution was analyzed by an HPLC using the developed method. The mixture of sample solution $(30 \mu \mathrm{L})$ with methanol $(180 \mu \mathrm{L})$ was used as a control. UV detection was recorded using the above analytical HPLC condition at the wavelength of $247 \mathrm{~nm}$. The decreases in peak areas are expressed as a quantitative reduction. The peak area reduction (PAR, \%) was calculated as follows: $(A a-A b) / A a \times 100 \%$, where $A a$ and $A b$ are the HPLC peak areas of the compound incubated without and with the DPPH methanol solution, respectively.

Radical scavenging assay (DPPH) - The DPPH assay was performed to determine the free radical scavenging activity of isolated compounds. Briefly, a $0.20 \mathrm{mM}$ solution of DPPH was previously prepared in methanol, after that $150 \mu \mathrm{L}$ of this solution was mixed to $50 \mu \mathrm{L}$ of each compounds at various concentrations $(50,25,5,1$ $\mu \mathrm{g} / \mathrm{mL}$ ) in methanol. After $15 \mathrm{~min}$ incubation in the dark room, the decrease in the absorbance of the solution was measured on a Titertek microplate reader at $517 \mathrm{~nm}$ (Multiskan MCC/340, MKII Microplate Reader). LAscorbic acid was used as the positive control. DPPH inhibitory activity was expressed as the percentage inhibition (\%) in the above assay system, and was calculated as $[1-(A s-A b / A c)] \times 100 \%$, where $A s$ is the absorbance of DPPH solution $(150 \mu \mathrm{L})$ with the sample solution $(50 \mu \mathrm{L})$; $A c$ is the absorbance of the DPPH solution $(150 \mu \mathrm{L})$ with methanol $(50 \mu \mathrm{L}) ; A b$ is the absorbance of methanol (150 $\mu \mathrm{L})$ with the sample solution $(50 \mu \mathrm{L})$. The results were expressed as $\mathrm{IC}_{50}(50 \%$ inhibitory concentration) values.

Cell lines and culture - Human promyelocytic leukemia (HL-60) cells, human cervical adenocarcinoma (HeLa) cells, and MCF-7 (human breast adenocarcinoma) cells, were obtained from the America Type Culture Collection (ATCC) and cultured as per the guidelines supplied. The cells were maintained in RPMI or IMDM (Gibco BRL, NY, USA) (containing: $10 \%$ fetal bovine serum, $2 \%$ penicillin, $100 \mu \mathrm{g} / \mathrm{mL}$ streptomycin, and $2 \mathrm{mM}$ L-glutamine) at $37^{\circ} \mathrm{C}$ in a $5 \% \mathrm{CO}_{2}$ incubator.

Cytotoxic activity assay - The cytotoxic activity was tested on MTT assay. ${ }^{10}$ Viable cells were plated at a density $1 \times 10^{4}$ cells/well into 96 -well microtiter plates and then incubated at $37^{\circ} \mathrm{C}$ in a $5 \% \mathrm{CO}_{2}$ incubator. The cells were further treated with test sample at different concentrations $(1,5,25$, and $50 \mu \mathrm{M})$ added in DMSOdissolved stock solution and the final DMSO concentration was not over $0.1 \%$. The cells were cultured for $48 \mathrm{~h}$, and they were then incubated with MTT (a $5 \mu \mathrm{g} / \mathrm{mL}$ final concentration) for $4 \mathrm{~h}$. After centrifuging for $5 \mathrm{~min}$ at $1500 \mathrm{rpm}$, the medium in plates was removed, and resulting formazan crystals were dissolved in DMSO. The optical density was measured on a Titertek microplate reader at $570 \mathrm{~nm}$ (Multiskan MCC/340, MKII Microplate Reader). The cytotoxicity was expressed as $\mathrm{IC}_{50}(50 \%$ inhibitory concentration) value.

Statistical analysis-Tests were conducted in the means triplicate assays \pm standard deviation. The statistical significance was determined by using SPSS software (Version 22.0, SPSS Inc. Chicago, IL, USA). Statistical significances were defined at $p \leq 0.05$.

Optimization of chromatographic condition - The isolated compounds $(\mathbf{1}-\mathbf{1 0})$ were first tested for purity. All the compounds were evaluated with above $98 \%$ pure by using HPLC/PDA system; therefore, their absorbance was measured. Compounds $\mathbf{1 - 3}$, and 5 provided the same absorbance characteristics with a maximum at 233 nm meanwhile compounds $\mathbf{4}$ and $\mathbf{6}-\mathbf{1 0}$ also displayed the same absorbance characteristics with a maximum at 327 $\mathrm{nm}$ within the range $190-400 \mathrm{~nm}$ in UV scanning. Hence, the wavelength of $233 \mathrm{~nm}$ was used for compounds $\mathbf{1}-\mathbf{3}$, and 5, and the wavelength of $327 \mathrm{~nm}$ was used for compounds 4 and $6-10$. The mobile phase comprising methanol and water containing $0.1 \%$ formic acid system was initially tried to develop a separation method. However, that system was unsatisfactory for separating major components. Acetonitrile (A) and water containing $0.1 \%$ formic acid (B) system were used to improve the separation. Finally, a simple gradient solvent system elution method from 93:7 (B) to 65:35 (B) for 30 min was used. Isochlorogenic acid with a retention time of 19.5 min was selected as an internal standard. Ten marker compounds were well separated without overlapping of adjacent peaks. The chromatographic peaks of the analytes in the sample solution were determined by comparing their retention times with those of the individual standards, and were confirmed by spiking the samples with the individual compounds.

Optimization of sample preparation conditionSample preparation: The dried roots of P. umbrosa were grinded for $5 \mathrm{~min}$ and were then sieved through a $250 \mu \mathrm{m}$ sieve to ensure required sample homogeneity. The mixtures of solvent systems were used as following: $95 \%, 75 \%$, 
$50 \%, 25 \%$ ethanol and $100 \%, 75 \%, 50 \%, 25 \%$ methanol for extraction solvents. The P. umbrosa samples $(0.5 \mathrm{~g})$ extracted with $25 \mathrm{~mL}$ of above solvents for $30 \mathrm{~min}$ at room temperature in an ultrasonic bath. As a result, the best compound peak area/I. S. areas were obtained at sample $100 \%$ methanol used. Therefore, $100 \%$ methanol

Table 1. Linearity, linear range, LOD, and LOQ

\begin{tabular}{ccccccc}
\hline \hline Analyte & $\begin{array}{c}\text { Linear range } \\
(\mu \mathrm{g} / \mathrm{mL})\end{array}$ & Slope & Intercept & $\begin{array}{c}\text { Correlation } \\
\text { coefficient }\left(r^{2}\right)\end{array}$ & $\begin{array}{c}\text { LOD } \\
(\mu \mathrm{g} / \mathrm{mL})\end{array}$ & $\begin{array}{c}\text { LOQ } \\
(\mu \mathrm{g} / \mathrm{mL})\end{array}$ \\
\hline $\mathbf{1}$ & $0.625-500$ & 0.0098 & -0.0437 & 0.9992 & 0.430 & 1.435 \\
$\mathbf{2}$ & $0.625-500$ & 0.0104 & 0.0646 & 0.9994 & 0.080 & 0.267 \\
$\mathbf{3}$ & $0.625-500$ & 0.0120 & 0.0933 & 0.9997 & 0.060 & 0.200 \\
$\mathbf{4}$ & $0.625-500$ & 0.0990 & 0.0383 & 0.9996 & 0.071 & 0.235 \\
$\mathbf{5}$ & $0.625-500$ & 0.0100 & 0.1057 & 0.9982 & 0.066 & 0.220 \\
$\mathbf{6}$ & $0.625-500$ & 0.0127 & 0.0558 & 0.9997 & 0.212 & 0.708 \\
$\mathbf{7}$ & $0.625-500$ & 0.0122 & 0.0512 & 0.9997 & 0.013 & 0.042 \\
$\mathbf{8}$ & $0.625-500$ & 0.0083 & 0.0825 & 0.9987 & 0.028 & 0.094 \\
$\mathbf{9}$ & $0.625-500$ & 0.0103 & 0.1043 & 0.9986 & 0.027 & 0.091 \\
$\mathbf{1 0}$ & $0.625-500$ & 0.0089 & 0.0806 & 0.9996 & 0.026 & 0.088 \\
\hline
\end{tabular}

Table 2. Intra- and inter-day precisions of the 10 marker compounds in $\mathrm{MeOH}$ extract of the Phlomidis Radix

\begin{tabular}{|c|c|c|c|c|c|c|c|c|c|c|c|}
\hline \multirow[b]{2}{*}{ Analyte } & \multirow{2}{*}{$\begin{array}{c}\text { Fortified } \\
\text { conc. } \\
(\mu \mathrm{g} / \mathrm{mL})\end{array}$} & \multirow{2}{*}{$\begin{array}{l}\text { Sample } \\
\text { conc. } \\
(\mu \mathrm{g} / \mathrm{mL})\end{array}$} & \multicolumn{4}{|c|}{ Intra-day $(n=5)$} & \multirow{2}{*}{$\begin{array}{c}\text { Sample } \\
\text { conc. } \\
(\mu \mathrm{g} / \mathrm{mL})\end{array}$} & \multicolumn{4}{|c|}{ Inter-day $(n=5)$} \\
\hline & & & $\begin{array}{c}\text { Observed } \\
(\mu \mathrm{g} / \mathrm{mL})\end{array}$ & SD & $\begin{array}{c}\text { Accuracy } \\
(\%)\end{array}$ & $\begin{array}{c}\text { Precision } \\
(\%)\end{array}$ & & $\begin{array}{c}\text { Observed } \\
(\mu \mathrm{g} / \mathrm{mL})\end{array}$ & SD & $\begin{array}{c}\text { Accuracy } \\
(\%)\end{array}$ & $\begin{array}{c}\text { Precision } \\
(\%)\end{array}$ \\
\hline \multirow{3}{*}{1} & 1 & 27.49 & 28.34 & 0.12 & 84.87 & 1.15 & 27.80 & 28.38 & 0.05 & 88.93 & 1.72 \\
\hline & 50 & 27.49 & 77.20 & 0.03 & 99.40 & 0.30 & 27.80 & 77.14 & 0.14 & 99.30 & 0.71 \\
\hline & 200 & 27.49 & 226.98 & 0.19 & 99.74 & 0.19 & 27.80 & 227.07 & 0.37 & 99.79 & 0.49 \\
\hline \multirow{3}{*}{2} & 1 & 171.25 & 172.14 & 0.65 & 88.74 & 0.65 & 171.02 & 172.17 & 1.11 & 91.95 & 4.08 \\
\hline & 50 & 171.25 & 221.75 & 0.66 & 100.99 & 0.33 & 171.02 & 221.99 & 0.37 & 101.46 & 0.32 \\
\hline & 200 & 171.25 & 370.99 & 0.28 & 99.87 & 0.28 & 171.02 & 370.94 & 0.25 & 99.79 & 0.49 \\
\hline \multirow{3}{*}{3} & 1 & 22.21 & 23.26 & 0.28 & 105.08 & 2.81 & 22.63 & 23.25 & 0.31 & 104.14 & 1.44 \\
\hline & 50 & 22.21 & 73.05 & 0.27 & 101.67 & 0.26 & 22.63 & 72.92 & 0.10 & 101.41 & 0.32 \\
\hline & 200 & 22.21 & 222.80 & 0.30 & 100.29 & 0.30 & 22.63 & 223.04 & 0.30 & 100.42 & 0.21 \\
\hline \multirow{3}{*}{4} & 1 & 2.41 & 3.35 & 0.04 & 93.71 & 0.40 & 2.33 & 3.39 & 0.03 & 97.96 & 2.77 \\
\hline & 50 & 2.41 & 53.65 & 0.37 & 102.47 & 0.37 & 2.33 & 53.53 & 0.40 & 102.23 & 0.30 \\
\hline & 200 & 2.41 & 202.70 & 0.34 & 100.14 & 0.34 & 2.33 & 202.76 & 0.38 & 100.18 & 0.38 \\
\hline \multirow{3}{*}{5} & 1 & 100.35 & 101.45 & 0.51 & 110.28 & 0.51 & 100.97 & 101.43 & 0.34 & 108.15 & 3.02 \\
\hline & 50 & 100.35 & 151.15 & 0.71 & 101.61 & 0.71 & 100.97 & 150.97 & 0.70 & 101.24 & 0.34 \\
\hline & 200 & 100.35 & 300.64 & 0.58 & 100.15 & 0.58 & 100.97 & 300.94 & 0.80 & 100.29 & 0.52 \\
\hline \multirow{3}{*}{6} & 1 & 193.31 & 194.30 & 0.32 & 97.96 & 3.28 & 193.14 & 194.14 & 0.18 & 82.43 & 2.45 \\
\hline & 50 & 193.31 & 243.13 & 0.57 & 99.63 & 0.57 & 193.14 & 242.68 & 0.25 & 100.38 & 0.22 \\
\hline & 200 & 193.31 & 391.92 & 0.31 & 99.30 & 0.31 & 193.14 & 391.48 & 0.18 & 99.08 & 0.58 \\
\hline \multirow{3}{*}{7} & 1 & 41.66 & 42.64 & 0.40 & 98.17 & 4.04 & 41.87 & 42.66 & 0.19 & 100.22 & 2.85 \\
\hline & 50 & 41.66 & 92.30 & 0.40 & 101.28 & 0.40 & 41.87 & 92.27 & 0.26 & 101.21 & 0.25 \\
\hline & 200 & 41.66 & 240.95 & 0.72 & 99.64 & 0.72 & 41.87 & 240.67 & 0.18 & 99.51 & 0.18 \\
\hline \multirow{3}{*}{8} & 1 & 16.66 & 17.59 & 0.66 & 93.54 & 0.66 & 16.71 & 17.46 & 0.39 & 80.56 & 4.83 \\
\hline & 50 & 16.66 & 67.03 & 0.30 & 100.75 & 0.30 & 16.71 & 66.84 & 0.22 & 100.38 & 0.22 \\
\hline & 200 & 16.66 & 216.05 & 0.29 & 99.70 & 0.29 & 16.71 & 216.65 & 0.18 & 100.00 & 0.18 \\
\hline \multirow{3}{*}{9} & 1 & 19.35 & 20.39 & 0.61 & 104.08 & 0.61 & 19.39 & 20.47 & 4.36 & 111.34 & 3.86 \\
\hline & 50 & 19.35 & 70.36 & 0.38 & 102.00 & 0.38 & 19.39 & 70.45 & 0.30 & 102.19 & 0.30 \\
\hline & 200 & 19.35 & 218.97 & 0.28 & 99.81 & 0.28 & 19.39 & 219.25 & 0.34 & 99.95 & 0.34 \\
\hline \multirow{3}{*}{10} & 1 & 8.01 & 9.09 & 0.21 & 108.30 & 2.14 & 8.21 & 9.13 & 0.43 & 111.99 & 3.86 \\
\hline & 50 & 8.01 & 58.13 & 0.28 & 100.25 & 0.18 & 8.21 & 58.47 & 0.36 & 100.91 & 0.36 \\
\hline & 200 & 8.01 & 208.50 & 0.42 & 100.25 & 0.42 & 8.21 & 208.38 & 0.43 & 100.19 & 0.43 \\
\hline
\end{tabular}


was selected for extraction solvent. In comparison between ultra-sonication and reflux method using 100\% methanol extraction solvent, the sample assay results were superior after extraction with sonication than with reflux. The time needed for complete extraction was determined with five lengths of time $(30,45,60,75$, and $90 \mathrm{~min})$ in $100 \%$ methanol via sonication at room temperature. The extraction time for $60 \mathrm{~min}$ yielded similar sample assay results as $75 \mathrm{~min}$. Thus, the compounds were thoroughly extracted when the time was $60 \mathrm{~min}$.

Linearity - The linearity of the developed method was validated by analyzing eight concentrations of each analytein the range of 0.625 to $500 \mu \mathrm{g} / \mathrm{mL}$. The concentration range is generally chosen as per International Conference on Harmonization guidelines. Triplicate analysis for each analyte was carried out. The linearity regression parameters of the calibration curves with correlation coefficients ranging between 0.9982 and 0.9997 are listed in Table 1. The LOD of these isolated constituents were determined to be 0.013 to $0.430 \mu \mathrm{g} / \mathrm{mL}$ and the LOQ was 0.042 to $1.435 \mu \mathrm{g} / \mathrm{mL}$ indicating that the developed method for the roots of $P$. umbrosa exhibited good sensitivity.

Precision and accuracy - The accuracy of the developed HPLC method was determined by analyzing the known amounts of analytes spiked into methanol extract solution of the roots of $P$. umbrosa. After addition of known amounts of each analyte to the previous methanol extract, solution recovery studies were examined. The results were shown in Table 2. The method precision was measured by six successive injections, and the precisions were less than $3.28 \%$ in intra-day and $4.83 \%$ in inter-day. The accuracies of the method were in the range $84.87-$ $105.08 \%$ in intra-day and $80.56-111.34 \%$ in inter-day. The method validation indicated that the regression equations of the marker compounds were linear and this method was precise, accurate, and reliable for quantitation of the 10 marker compounds $(\mathbf{1}-\mathbf{1 0})$.

Stability - The stability of the analytes at room temperature was measured at $0,1,3,7,15$, and 30 days. Under lightless temperature $\left(25^{\circ} \mathrm{C}\right)$ and $4{ }^{\circ} \mathrm{C}$, all marker compounds $(\mathbf{1}-\mathbf{1 0})$ displayed stable with recovery ranging from 97.39 to $100.93 \%$. The results were shown in Table 3 .

\section{Results and discussion}

Chromatographic separation and purification of $n$ $\mathrm{BuOH}$ fraction from the roots of $P$. umbrosa led to the isolation of 10 compounds $(\mathbf{1}-\mathbf{1 0})$. These compounds $(\mathbf{1}-$ 10) were identified as lamalbid (1), ${ }^{11}$ sesamoside (2), ${ }^{12}$ shanzhiside methyl ester (3), ${ }^{12}$ chlorogenic acid (4), ${ }^{13}$

Table 3. Stability of 10 marker compounds $(\mathbf{1}-\mathbf{1 0})$

\begin{tabular}{|c|c|c|c|c|c|c|c|c|c|}
\hline \multirow{2}{*}{ Compound } & \multirow{2}{*}{$\begin{array}{c}\text { Temperature } \\
\left({ }^{\circ} \mathrm{C}\right)\end{array}$} & \multicolumn{6}{|c|}{ Day (\%) } & \multirow{2}{*}{ Mean } & \multirow{2}{*}{$\begin{array}{l}\text { RSD } \\
(\%)\end{array}$} \\
\hline & & 0 & 1 & 3 & 7 & 15 & 30 & & \\
\hline \multirow{2}{*}{1} & 4 & 100 & 101.30 & 101.58 & 100.19 & 101.22 & 101.27 & 100.93 & 0.65 \\
\hline & 25 & 100 & 97.32 & 101.35 & 98.44 & 101.12 & 100.9 & 99.86 & 1.64 \\
\hline \multirow{2}{*}{2} & 4 & 100 & 99.90 & 101.88 & 102.03 & 100.66 & 100.30 & 100.80 & 0.93 \\
\hline & 25 & 100 & 98.12 & 98.75 & 99.35 & 98.10 & 95.74 & 98.34 & 1.49 \\
\hline \multirow{2}{*}{3} & 4 & 100 & 98.31 & 99.15 & 101.37 & 99.75 & 99.78 & 99.72 & 1.01 \\
\hline & 25 & 100 & 96.95 & 97.52 & 99.37 & 98.94 & 100.81 & 98.93 & 1.48 \\
\hline \multirow{2}{*}{4} & 4 & 100 & 99.05 & 100.80 & 101.33 & 100.84 & 100.88 & 100.48 & 0.82 \\
\hline & 25 & 100 & 97.01 & 101.10 & 97.02 & 98.66 & 98.01 & 98.63 & 1.67 \\
\hline \multirow{2}{*}{5} & 4 & 100 & 99.70 & 100.25 & 99.34 & 97.56 & 96.97 & 98.97 & 1.38 \\
\hline & 25 & 100 & 98.74 & 96.60 & 96.77 & 97.45 & 98.06 & 97.94 & 1.32 \\
\hline \multirow{2}{*}{6} & 4 & 100 & 97.31 & 97.73 & 100.26 & 100.60 & 99.59 & 99.25 & 1.40 \\
\hline & 25 & 100 & 97.66 & 95.61 & 97.93 & 98.05 & 95.06 & 97.39 & 1.85 \\
\hline \multirow{2}{*}{7} & 4 & 100 & 98.36 & 100.21 & 102.41 & 101.00 & 101.99 & 100.66 & 1.47 \\
\hline & 25 & 100 & 98.86 & 99.70 & 100.10 & 98.13 & 97.95 & 99.12 & 0.96 \\
\hline \multirow{2}{*}{8} & 4 & 100 & 97.23 & 97.52 & 99.95 & 96.41 & 97.32 & 98.07 & 1.55 \\
\hline & 25 & 100 & 96.61 & 96.61 & 98.62 & 99.33 & 98.70 & 98.31 & 1.43 \\
\hline \multirow{2}{*}{9} & 4 & 100 & 99.80 & 102.13 & 100.85 & 100.12 & 100.89 & 100.63 & 0.86 \\
\hline & 25 & 100 & 98.54 & 96.00 & 97.96 & 98.34 & 97.29 & 98.02 & 1.36 \\
\hline \multirow{2}{*}{10} & 4 & 100 & 100.70 & 98.29 & 101.52 & 98.38 & 97.77 & 99.44 & 1.52 \\
\hline & 25 & 100 & 98.31 & 97.50 & 99.20 & 98.32 & 97.99 & 98.55 & 0.91 \\
\hline
\end{tabular}




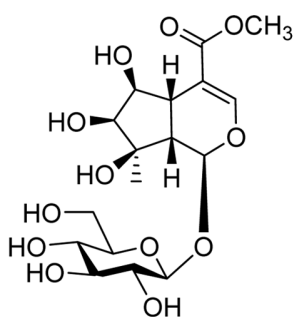

1<smiles>O=C(/C=C/c1ccc(O)c(O)c1)OC1C[C@](O)(C(=O)O)C[C@H](O)[C@H]1O</smiles>

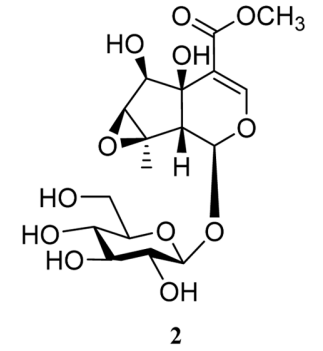

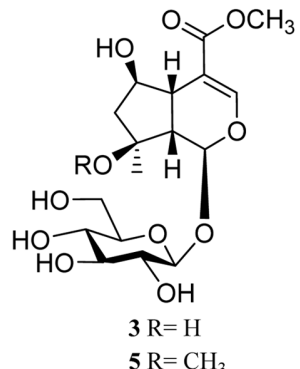

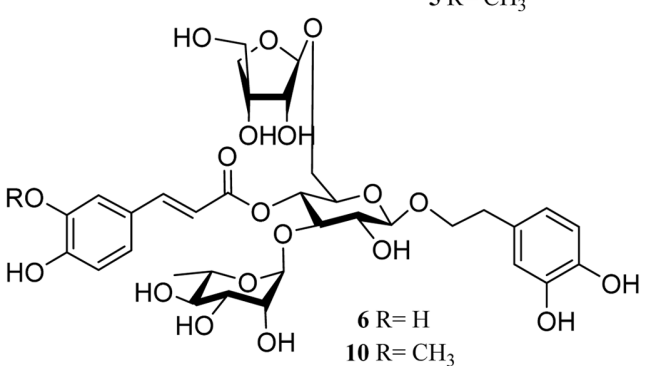<smiles>[R]OC(OC(=O)/C=C/c1ccc(O)c(O)c1)C(O)COC(O)C(O)COCCc1ccc(O)c(O)c1</smiles>

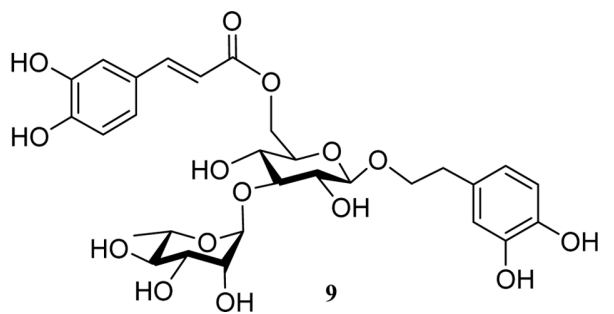

Fig. 1. The structures of the isolates from the roots of P. umbrosa.

Table 4. Contents of marker compounds in P. umbrosa samples

\begin{tabular}{cccccc}
\hline \hline Compound & PU1 & PU2 & PU3 & PU4 & PU5 \\
\hline $\mathbf{1}$ & $0.139 \pm 0.001$ & $0.245 \pm 0.010$ & $0.399 \pm 0.017$ & $0.404 \pm 0.013$ & $0.311 \pm 0.005$ \\
$\mathbf{2}$ & $0.855 \pm 0.005$ & $1.732 \pm 0.014$ & $1.248 \pm 0.016$ & $1.384 \pm 0.002$ & $1.567 \pm 0.021$ \\
$\mathbf{3}$ & $0.113 \pm 0.002$ & $0.254 \pm 0.010$ & $0.281 \pm 0.005$ & $0.188 \pm 0.007$ & $0.288 \pm 0.021$ \\
$\mathbf{4}$ & $0.012 \pm 0.003$ & $0.264 \pm 0.012$ & $0.040 \pm 0.005$ & $0.060 \pm 0.002$ & $0.126 \pm 0.006$ \\
$\mathbf{5}$ & $0.505 \pm 0.002$ & $0.937 \pm 0.003$ & $0.658 \pm 0.008$ & $0.831 \pm 0.012$ & $0.963 \pm 0.037$ \\
$\mathbf{6}$ & $0.966 \pm 0.001$ & $2.111 \pm 0.025$ & $0.349 \pm 0.007$ & $0.613 \pm 0.001$ & $0.958 \pm 0.010$ \\
$\mathbf{7}$ & $0.209 \pm 0.002$ & $0.819 \pm 0.009$ & $0.284 \pm 0.001$ & $0.253 \pm 0.005$ & $0.396 \pm 0.018$ \\
$\mathbf{8}$ & $0.084 \pm 0.001$ & $0.187 \pm 0.014$ & $0.022 \pm 0.003$ & $0.047 \pm 0.007$ & $0.108 \pm 0.005$ \\
$\mathbf{9}$ & $0.097 \pm 0.001$ & $0.259 \pm 0.003$ & $0.040 \pm 0.001$ & $0.060 \pm 0.008$ & $0.087 \pm 0.003$ \\
$\mathbf{1 0}$ & $0.041 \pm 0.001$ & $0.085 \pm 0.013$ & $0.032 \pm 0.001$ & $0.001 \pm 0.001$ & $0.043 \pm 0.004$ \\
\hline
\end{tabular}

barlerin (5), 11 forsythoside B (6), ${ }^{14} 1$ '- $O-\beta$-(3,4-dihydroxyphenyl)-ethyl-4'-O-caffeoyl- $\alpha$-L-fucopyranosyl-(1 $\rightarrow$ 3')- $\beta$-D-glucopyranoside (7), ${ }^{15}$ verbascoside (8), ${ }^{1}$ isoverbascoside (9), ${ }^{16}$ alyssonoside $(\mathbf{1 0})^{14}$ by comparison of their ${ }^{1} \mathrm{H}$ and ${ }^{13} \mathrm{C}$ NMR with those reported data (Fig. 1).

A gradient RP-C18 HPLC system was performed for the simultaneous quantitative determination of 10 compounds $(\mathbf{1}-\mathbf{1 0})$. The contents of isolated constituents from the roots of $P$. umbrosa were listed in Table 4. The major constituents in five different samples were com- pounds $\mathbf{2}, \mathbf{5}$, and $\mathbf{6}$ at the concentrations of $0.855 \pm 0.05$ to $1.732 \pm 0.014,0.505 \pm 0.02$ to $0.937 \pm 0.03$, and $0.349 \pm$ 0.07 to $2.111 \pm 0.025 \%$ on dry weight basis, respectively. To elucidate the chemical constituents between $D$. asperoides and $P$. umbrosa, the $D$. asperoides samples were also analyzed by the developed method. The results exhibited that all the marker compounds $(\mathbf{1}-\mathbf{1 0})$ in the $D$. asperoides samples disappeared in the chromatogram (Fig. 2C) except for compound $4(0.919 \pm 0.002 \%)$. This evidence indicated that such misusage between Phlomidis 

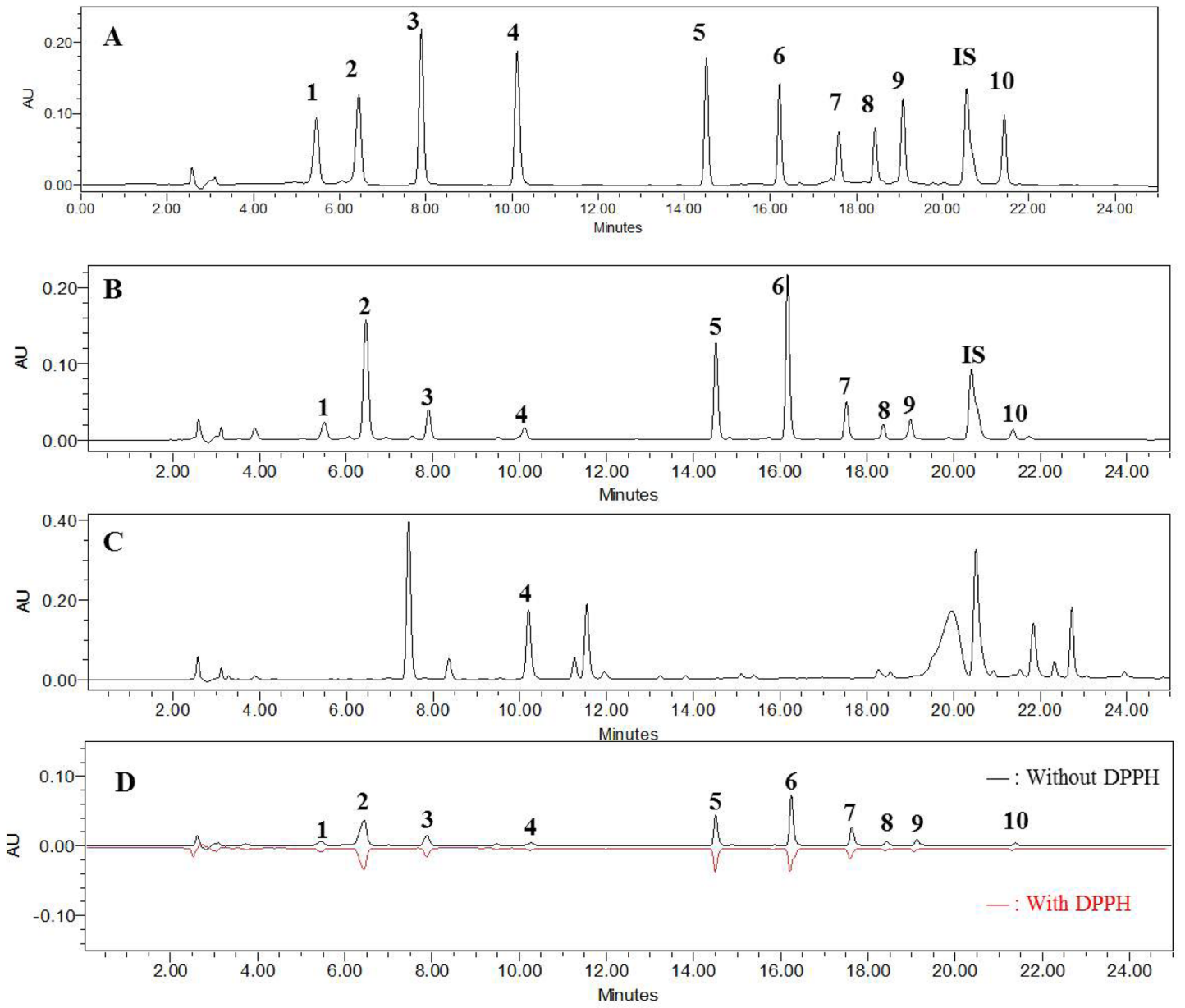

Fig. 2. The HPLC chromatograms at wavelength of $247 \mathrm{~nm}$ for the standard mixture (A), Phlomidis Radix extract (B), Dipsaci Radix extract (C), and Phlomidis Radix extract without and with DPPH (D), isochlorogenic acid (IS).

Radix and Dipsaci Radix was incorrect.

The potential anti-oxidant activities of marker compounds in the methanol extract were simply identified by the DPPH-HPLC. The peak areas of anti-oxidants will decrease or disappear in the HPLC chromatogram after spiking with DPPH. In our results, the peak areas of all 10 peaks were decreased after spiking with DPPH (Fig. 2). When 10 compounds exist together, phenylethanoid (4 and 6-9) first react with DPPH. Particularly, phenylethanoid compounds, 4 and $\mathbf{6}-\mathbf{9}$, significantly reduced the peak areas with PAR values ranging from $47.4 \pm 0.2$ to $67.8 \pm 1.0 \%$ (Table 5). Compound 6 displayed the highest DPPH-radical scavenging activity with PAR value of $67.8 \pm 1.0 \%$. Compounds $7-9$ showed considerable scavenging capacities with PAR values of $58.1 \pm 0.9,59.6$ \pm 0.2 , and $62.7 \pm 0.6 \%$, respectively. While phenylethanoid compound 10 exhibited the weakest one $(\mathrm{PAR}=35.4 \pm$ $0.2 \%$ ). In contrast, iridoid compounds, $\mathbf{1}-\mathbf{3}$ and $\mathbf{5}$, displayed low DPPH scavenging capacity with PAR
Table 5. The anti-oxidant capacities of isolated compounds (110) and their peak area reduction in the methanol extract by DPPH-HPLC from Phlomidis Radix

\begin{tabular}{ccc}
\hline \hline Compounds & $\mathrm{IC}_{50}(\mu \mathrm{M})^{\mathrm{b}}$ & PAR $(\%)^{\mathrm{a}}$ \\
\hline $\mathbf{1}$ & $>50$ & $20.5 \pm 0.3$ \\
$\mathbf{2}$ & $>50$ & $25.7 \pm 0.1$ \\
$\mathbf{3}$ & $>50$ & $33.9 \pm 0.5$ \\
$\mathbf{4}$ & $27.7 \pm 2.4$ & $47.4 \pm 0.2$ \\
$\mathbf{5}$ & $>50$ & $38.3 \pm 1.0$ \\
$\mathbf{6}$ & $10.2 \pm 1.1$ & $67.8 \pm 1.0$ \\
$\mathbf{7}$ & $18.0 \pm 0.8$ & $58.1 \pm 0.9$ \\
$\mathbf{8}$ & $19.1 \pm 0.3$ & $59.6 \pm 0.2$ \\
$\mathbf{9}$ & $19.9 \pm 0.6$ & $62.7 \pm 0.6$ \\
$\mathbf{1 0}$ & $>50$ & $35.4 \pm 0.2$ \\
L-Ascorbic acid $^{\mathrm{c}}$ & $2.5 \pm 0.2$ &
\end{tabular}

${ }^{\text {aPAR }}$ is the peak area reduction calculated from DPPH-HPLC. ${ }^{\mathrm{b}} \mathrm{IC}_{50}$ indicates the concentration of tested compound necessary to decrease the initial concentration of DPPH by $50 \%$.

${ }^{\mathrm{c}} \mathrm{L}$-Ascorbic acid was used as the positive control. 
values ranging from $20.5 \pm 0.3$ to $38.3 \pm 1.0 \%$. All these results are in agreement with the individual compounds tested where compound $\mathbf{6}$ showed the highest anti-oxidant capacity.

DPPH assay was used to determine the anti-oxidant capacities of isolated compounds $(\mathbf{1}-\mathbf{1 0})$. The results were reported in Table 1. Most of phenylethanoid compounds (4 and 6-9) displayed high anti-oxidant capacities with $\mathrm{IC}_{50}$ values of $27.7 \pm 2.4,10.2 \pm 1.1,18.0 \pm 0.8,19.1 \pm$ 0.3 , and $19.9 \pm 0.6 \mu \mathrm{M}$, respectively. L-Ascorbic acid was used as the positive control with $\mathrm{IC}_{50}$ value of $2.5 \pm$ $0.2 \mu \mathrm{M}$. In contrast, iridoid compounds $(\mathbf{1}-\mathbf{3}$ and $\mathbf{5})$ and phenylethanoid compound $\mathbf{1 0}$ were inactive $\left(\mathrm{IC}_{50}\right.$ values $>$ $50 \mu \mathrm{M}$ ) (Table 5). DPPH free radical scavenging method is often used for evaluating the anti-oxidant potential of a compound or an extract. This is a rapid, simple, and widely used method to test the anti-oxidant activity. DPPH can accept an electron or hydrogen radical to become a stable and diamagnetic molecule. In general, the compounds possessing potent hydrogen donors are capable for reacting with DPPH radicals. The compounds with several hydroxyl groups could serve as hydrogen donors. Therefore, compounds 4 and 6 - 9 having several hydroxyl groups in aromatic ring may display stronger DPPH radical scavenging activities.

The cytotoxic activity of the isolates $(\mathbf{1}-\mathbf{1 0})$ was evaluated against HL-60 as well as MCF-7 and Hela cell lines. The inhibitory process was assessed by MTT assay. According to the results, compounds $(\mathbf{6}, \mathbf{8}$, and 9$)$ significantly showed cytotoxic effects against HL-60 cell lines with $\mathrm{IC}_{50}$ values of $35.4 \pm 3.1,18.6 \pm 2.0$, and $42.9 \pm 3.0$ $\mu \mathrm{M}$, respectively. Whereas, iridoids $(\mathbf{1}-\mathbf{3}$ and $\mathbf{5})$ and phenylethanoids $(\mathbf{4}, \mathbf{7}$, and $\mathbf{1 0})$ were inactive $\left(\mathrm{IC}_{50}\right.$ values $>50 \mu \mathrm{M})$. These compounds were also tested against MCF-7 and HeLa cell lines. Nevertheless, all the isolates displayed very weak or inactive $\left(\mathrm{IC}_{50}\right.$ value $\left.>50 \mu \mathrm{M}\right)$ (Table 6).

Four iridoids (1-3 and 5) and six phenylethanoid derivatives $(4,6-10)$ were isolated from the roots of $P$. umbrosa. Particularly, a new analytical HPLC/PDA method has been developed, validated, and successfully applied to determine the 10 marker compounds $(\mathbf{1}-\mathbf{1 0})$ in the roots of $P$. umbrosa. In DPPH assay, compounds 4 and 6-9 showed considerable anti-oxidant effects. In addition, these compounds were also evaluated and exhibited significant peak area reduction by using the DPPH-HPLC system. All the isolated compounds were further tested in cancer cell lines (HL-60). Compound 8 displayed significant cytotoxic activity against HL-60. Compounds 6 and 9 showed moderate cytotoxic effects
Table 6. The cytotoxic activities of compounds $\mathbf{6}, \mathbf{8}$, and 9 from the roots of $P$. umbrosa

\begin{tabular}{cc}
\hline \hline \multirow{2}{*}{ Compound } & $\mathrm{IC}_{50}$ value $(\mu \mathrm{M})^{\mathrm{a}}$ \\
\cline { 2 - 2 } & HL-60 \\
\hline $\mathbf{6}$ & $35.4 \pm 3.1$ \\
$\mathbf{8}$ & $18.6 \pm 2.0$ \\
$\mathbf{9}$ & $42.9 \pm 3.0$ \\
Adriamycin $^{\mathrm{b}}$ & $2.5 \pm 0.3$ \\
\hline
\end{tabular}

${ }^{\mathrm{a}} \mathrm{IC}_{50}$ values were calculated on the basis of the results of three independent tests.

${ }^{\mathrm{b}}$ Adriamycin was used as the positive control.

against HL-60. These results suggested that roots of $P$. umbrosa may be a potent functional food or pharmaceutical ingredient as an anti-oxidant.

\section{Acknowledgments}

This research was supported by a grant (16182KFDA 225) from Korea Food and Drug Administration in 2016.

\section{References}

(1) Andary, C.; Wylde, R.; Laffite, C.; Privat, G.; Winternitz, F. Phytochemistry 1982, 21, 1123-1127.

(2) Zhang, Y.; Wang, Z. Z. J. Pharm. Biomed. Anal. 2008, 47, 213-217.

(3) Liu, P.; Takaishi, T.; Duan, H. Q. Chin. Chem. Lett. 2007, 18, 155157.

(4) Limem-Ben Amor, I.; Boubaker, J.; Ben Sgaier, M.; Skandrani, I.; Bhouri, W.; Neffati, A.; Kilani, S.; Bouhlel, I.; Ghedira, K.; ChekirGhedira, L. J. Ethnopharmacol. 2009, 125, 183-202.

(5) Zhang, Y.; Wang, Z. Z. C. R. Biol. 2009, 332, 816-826.

(6) Yun, J. S.; Kim, J.; Choi, J.; Kwon, K.; Jo, C. H. Korean J. Food Sci. Technol. 2016, 48, 531-535.

(7) Ministry of Food and Drug Safety. The Korean herbal pharmacopoeia; Shinil Books: Korea, 2013, pp 250-251.

(8) Ministry of Food and Drug Safety. The Korean herbal pharmacopoeia; Shinil Books: Korea, 2013, pp 430-431.

(9) Fang, L.; Zhang, H.; Zhou, J.; Geng, Y.; Wang, X. J. Anal. Methods Chem. 2018, 2018, 3158293-3158299.

(10) Angius, F.; Floris, A. Toxicol. In Vitro. 2015, 29, 314-319.

(11) Kobayashi, S.; Mima, A.; Kihara, M.; Imakura, Y. Chem. Pharm. Bull. 1986, 34, 876-880.

(12) Kasai, R.; Katagiri, M.; Ohtani, K.; Yamasaki, K.; Yang, C. R.; Tanaka, O. Phytochemistry 1994, 36, 967-970.

(13) Clifford, M. N.; Johnston, K. L.; Knight, S.; Kuhnert, N. J. Agric. Food Chem. 2003, 51, 2900-2911.

(14) Saracoglu, I.; Kojima, K.; Harput, U. S.; Ogihara, Y. Chem. Pharm. Bull. 1998, 46, 726-727.

(15) Suo, M.; Ohta, T.; Takano, F.; Jin, S. Molecules 2013, 18, 7336-7345. (16) Li, L.; Tsao, R.; Liu, Z.; Liu, S.; Yang, R.; Young, J. C.; Zhu, H.; Deng, Z.; Xie, M.; Fu, Z. J. Chromatogr. A 2005, 1063, 161-169.

Received February 25, 2019 Revised April 17, 2019 Accepted April 17, 2019 